\title{
La educación y formación de la conciencia moral de los jóvenes
}

\section{Lorenzo Tébar Belmonte ${ }^{1}$}

\section{RESUMEN:}

\author{
"Dos cosas llenan el ánimo de admiración y respeto: \\ el cielo estrellado sobre mí y la ley moral dentro de mí” (Kant). \\ "En la Ética, entendida como responsabilidad, \\ es donde se anuda el nudo mismo de lo subjetivo. Soy, porque \\ soy para otros". \\ (E. Levinas: Ética e infinito, p. 39).
}

Si la educación no se define como una experiencia ética, deja de ejercer una misión socializadora irremplazable. Algunas políticas educativas guían hacia un terreno confuso de una moral laica. Hablar de ética y moral deja perplejos a muchos educadores, presos de un reduccionismo pedagógico, o escasos de formación humanista. Formar los criterios éticos y morales de los niños y jóvenes exige claridad de conceptos y métodos formativos coherentes. Y en todo caso la integralidad del maestro. Todos los educandos deben aprender a darse y a cumplir normas que garanticen una convivencia respetuosa. La escuela tiene la tarea de poner los fundamentos y dar una iniciación ética y moral. Las diversas filosofías nos ayudan a entender esta doble dimensión. Pero deben ser los educadores, sobre todo, quienes formen sanos hábitos y den criterios que fundamenten la autonomía y responsabilidad social de cada educando, con una formación intelectual sólida que les ayude a cuestionar la trascendencia de sus actos y el sentido profundo de su existencia. Noble misión de sentido.

Palabras clave: Educación, humanizar, socialización

\section{ABSTRACT:}

If education is not defined as an ethical experience, stop socializing exercise irreplaceable mission. Some educational policies lead to a confusing field. Secular moral? Talk of ethics and morals perplexes many educators, teaching prisoners a reductionism, or short of humanistic education. Being ethical and moral standards of children and young people requires clarity of concepts and consistent training methods. All students must learn to shop and meet standards that ensure a respectful coexistence. The school has the task of putting the moral and ethical foundations and initiation. The various philosophies help us understand this double dimension. But they must be educators, but especially those who form healthy habits and give criteria to underpin the autonomy and social responsibility of each student with a solid intellectual formation to help them question the significance of their actions and the deeper meaning of their existence. Noble mission of sense.

Keywords: Education, Humanize, socialize

I Doctor en Ciencias de la Educación. Académico Universidad de la Salle Colombia. E-mail: ltebar@1asalle.es 


\section{Lo que nos educa}

La educación es la experiencia socializante esencialmente humanizadora. No se puede entender a la persona si la desligamos de los lazos sociales desde su nacimiento. La "neotenia" explica la imprescindible necesidad que tenemos de nuestros progenitores para subsistir. Educar es baño de cuidados, amor y solitud para que la vida llegue a su plenitud. De ahí que podamos definir la educación como prolongación de la paternidad-maternidad.

¿Qué es lo que realmente educa? Nuestros primeros pasos en el hogar permiten que surja la persona desde un marco referencial normativo. Es el primer proceso de "personalización" (personar= Resonar), donde se nos reconoce por nuestro nombre, como personas únicas, con lazos afectivos profundos. Le sucede la etapa socializadora por medio de la escolarización, la introducción en un mundo más amplio y complejo de relaciones sociales. En esta etapa heterónoma aprendemos a aceptar normas, organizaciones y formas de convivencia. Con estas normas vienen implícitos unos derechos y unos deberes y valores: "Respeto a los demás, para que los demás me respeten a mi”. Cumplimos unas normas, para que nos podamos organizar y vivir con mayor armonía y paz. En definitiva, esta primera experiencia de convivencia con un grupo amplio, nos socializa y nos permite descubrir la relación entre derechos y deberes. Por eso podemos decir que la educación es una experiencia ética, porque nos introduce en un mundo regulado por unas costumbres, por un estilo de vida, por unas normas. La vida se juega en el campo de las relaciones de todo tipo, que convergen en el ámbito de los objetivos educativos y de aprendizaje. Al final, podremos decir que la educación nos forja, nos configura y nos aporta lazos culturales, sociales, afectivos, cooperativos, potenciadores.

Siendo conscientes de la importancia y de la confusión lógica que existe entre los conceptos de Ética y Moral, revisamos estas notas, con intención clarificadora, dada la reiteración con la que aludimos a ambos términos. 


\section{Dos conceptos complementarios}

Es importante delimitar los campos a los que se extiende cada uno de estos dos conceptos, para saber la dimensión y competencias de cada uno. Incluso ajustar nuestras afirmaciones, según a quién y cómo afecta la formación y la experiencia vital de ambos.

\begin{tabular}{|c|c|c|}
\hline & ÉTICA & MORAL \\
\hline Fundamentos & $\begin{array}{l}\text { Motivación: ¿Qué vida quiero } \\
\text { vivir? } \\
\text { Principio universal: Humanidad. } \\
\text { Lo básico y normal para todos. } \\
\text { Teleológico: Objetivo universal. }\end{array}$ & $\begin{array}{l}\text { Sentimiento: ¿Cómo debo ac- } \\
\text { tuar? } \\
\text { Libertad personal y gratuidad. } \\
\text { Deontológico (valor de la per- } \\
\text { sona). } \\
\text { Concreta la ética del grupo. }\end{array}$ \\
\hline Origen & $\begin{array}{l}\text { Justicia: Buscar lo bueno y justo. } \\
\text { Vida buena, vida digna. } \\
\text { Ser buen ciudadano. } \\
\text { Regir la convivencia. }\end{array}$ & $\begin{array}{l}\text { Busca lo que es bueno en sí } \\
\text { mismo. } \\
\text { Tiene una orientación social. } \\
\text { El imperativo de la responsa- } \\
\text { bilidad. } \\
\text { Aparecen las "virtudes del } \\
\text { alma". }\end{array}$ \\
\hline Dimensión & $\begin{array}{l}\text { Heterónoma: Justicia objetiva. } \\
\text { Situarme en el lugar de los } \\
\text { demás. } \\
\text { Imperativo categórico. }\end{array}$ & $\begin{array}{l}\text { Autónoma: Subjetiva. } \\
\text { Basada en valores y principios. } \\
\text { El árbitro es la propia con- } \\
\text { ciencia. }\end{array}$ \\
\hline Ámbitos & $\begin{array}{l}\text { El orden natural, cósmico y } \\
\text { humano. } \\
\text { Esfera de la vida pública. Social. }\end{array}$ & Privado: Esfera personal. \\
\hline Función & $\begin{array}{l}\text { Dar consistencia a la vida hu- } \\
\text { mana. } \\
\text { Jerarquizar las dimensiones del } \\
\text { hombre por la inteligencia y la } \\
\text { voluntad. Regular la vida social. }\end{array}$ & $\begin{array}{l}\text { Responder a la llamada de la } \\
\text { conciencia y sistema de creen- } \\
\text { cias. } \\
\text { Busca lo más noble y mejor, } \\
\text { según sus convicciones. }\end{array}$ \\
\hline
\end{tabular}

La palabra ética procede del griego "ethos", que significa morada, lugar donde vivimos, carácter, modo de ser, que después pasó al latín con la raíz: "Mos-moris", con el matiz de "costumbre" (en referencia a la morada o hábitos y estilos de vida). En castellano usamos con frecuencia indistintamente ética y moral. Pero, ¿cuál es la diferencia entre estos dos términos? Vamos a complementar los rasgos del cuadro-síntesis precedente. 


\section{a. Ética:}

Podríamos decir que es la "moral común" básica, para todos, aceptando las distintas formas religiosas de moralidad pública o privada. Comprendería las mínimas reglas básicas para que coexistan proyectos plurales de vida. Adela Cortina la calificó como ética "Mínima" o de mínimos: Se trata de un proyecto de conveniencia, que incluya unos mínimos normativos comunes que hagan posible la expresión de los máximos morales de cada tradición, grupo o persona. Es una forma de articular y armonizar la pluralidad de principios morales. Esta ética básica permite elaborar las Constituciones nacionales y leyes de los países. A la ética se la sitúa en un nivel reflexivo sobre lo que es común o lo diferente de nuestros proyectos morales. Aquí prevalecen nuestros argumentos y criterios lógicos, mientras que en la Moral priman los principios más vitales y existenciales. La Ética tiene una perspectiva filosófica, pues se ocupa de los principios, normas y valores que hacen digna la vida humana, en general. La Ética nos evita caer en dogmatismos y en la falta de crítica, sin eliminar ni desplazar las orientaciones morales y las creencias de cada uno. Esta óptica filosófica es una garantía para la racionalidad de las normas, principios y obligaciones con las que nos guiamos en la vida.

En definitiva, podríamos afirmar que la Ética es una filosofía moral universal, que nos ayuda a dar coherencia a nuestra personalidad, con nuestra reflexión, con respecto al mundo que nos rodea. La Ética nos acerca a la Psicología, para ayudarnos a ser personas sociales, nos enseña a convivir en un mundo inhóspito. Es necesaria una Ética común para entender el pensamiento de Vygotski, cuando habla de la construcción social de la mente: "Somos lo que los demás nos ban ayudado a ser". Todos nos necesitamos, somos para los demás y todos construimos una familia humana, que debe caminar en paz y solidaridad. Nunca podríamos imaginarnos solos en el mundo. La Ética es un despertador del sentido de aventura que la vida tiene para cada uno, al lado de los demás seres humanos. La Ética tiene también el sentido trascendente al analizar las obligaciones que nos ligan a los demás y al carácter "religado" de la vida humana, entretejida de lazos y bienes comunes con toda la humanidad. Concluyamos con 
la necesidad de la ética para construir una vida ecológica, sostenible, humanizadora, de la que todos somos protagonistas y responsables.

\section{b. Moral:}

El pensador francés E. Durkheim reflexionó sobre la ciencia de lo social en su obra "La división del trabajo social", afirmando:

"Puede decirse que es moral todo lo que constituye fuente de solidaridad, todo lo que fuerza al hombre a contar con el otro, a regular sus movimientos con arreglo a algo más que los impulsos de su egoísmo. La moralidad es tanto más fuerte cuanto más numerosos son sus lazos y más fuertes. El hombre no es un ser moral sino por vivir en sociedad, puesto que la moralidad consiste en ser solidario a un grupo y varía como esta solidaridad. Haced que se desvanezca toda vida social y la vida moral se desvanecerá al mismo tiempo”.

El hombre es un ser moral por el mero hecho de ser libre, de no dejarse aprisionar por ningún tipo de código natural o histórico. Kant dijo que Rousseau era el "Newton del mundo de la moral". Evidentemente, se refería a que con sus ideas sobre la libertad del hombre, Rousseau era a la ética moderna lo que Newton a la nueva física. Para Kant los dos pilares de la moral moderna son el desinterés y la universalidad: La acción verdaderamente moral, la acción realmente humana será, en primer lugar y ante todo, la acción desinteresada, es decir, la que da fe de eso que es propio del hombre: la libertad. "En la buena voluntad veía el nuevo principio de la moralidad auténtica, expresión de libertad, de acción desinteresada y de preocupación por el interés general: Éstas son las tres grandes palabras de la moral moderna" (Ferry, I55).

La problemática moral aparece en el ser humano al plantearse valores que son superiores a la vida. Así lo interpreta el filósofo francés, Luc Ferry, que matiza su sentido con esta contundente afirmación: " $\mathrm{La}$ moral surge cuando los principios nos parecen tan elevados, tan "sagrados", que empezamos a considerar que valdría la pena arriesgar o incluso sacrificar nuestra vida para defenderlos" (Ferry, p. 287). Hay valores que arraigan en las personas de una forma vital, trascendentes, por los cuales se cree que merece arriesgar la propia vida, como vemos en los idealistas 
políticos, militares, misioneros y voluntarios comprometidos por la justicia o la paz.

La Moral define los principios, normas y valores de cada persona, grupo o generación que llevan a una vida buena y justa. Se desarrolla en la vida cotidiana, en las actividades que constituyen nuestro modo de ser. Reservamos el término Moral para responder a la pregunta “¿qué debemos hacer?”, mientras que la Ética responde al porqué debemos hacer lo que hacemos. "La vida moral no puede entenderse únicamente como un sistema de normas, principio y prácticas, sino como un sistema de acciones significativas".

Sabemos que toda tradición religiosa comporta una doctrina moral, es decir, una forma de conducta que se rige por el sistema de creencias. Podríamos decir que el orden moral tiene relación directa con la fe que profesamos. Estos códigos morales religiosos constituyen el "estilo ético" -en otras culturas se le llama "ethos" - o talante moral específico. Estas expresiones de moralidad las encontramos en todas las religiones: "Clásicamente, por ejemplo, se reconoce que el etbos del Judaísmo es la sumisión incondicional al derecho divino, manifestado en la palabra sagrada recitada y en el decurso de la vida; el del Budismo sería la "recta acción" en el sentido de una acción inocua y compasiva; el del Cristianismo sería la vida desplegada desde el amor a Dios y a su comunicación entre las criaturas. Parece que la atención y la obediencia a la divinidad y el respeto al semejante podrían considerarse un patrimonio ético - moral- común a las diversas tradiciones religiosas de la bumanidad”. (Sánchez, J.L. (427).

\section{El desarrollo moral: la construcción moral del niño}

Los estudios realizados por Kohlberg sobre el desarrollo moral, partiendo de los estadios del juicio moral establecidos por Piaget, han constituido el norte que sustenta la visión más completa, para conocer los procesos cognitivo-evolutivos en los que se da el desarrollo moral en los niños, por la interacción de dichos procesos. El propio Kohlberg, tras la presentación de su tesis doctoral en I968, siguió investigando, durante 40 años, hasta su muerte en I987, para validar su propia teoría en la Universidad de Harvard. En 1975 
divulgó programas de Educación Moral por medio de debates sobre dilemas morales, desarrolló los programas en escuelas alternativas y de comunidad justa, que promovían la participación democrática y la madurez moral, basada en programas de formación moral de adolescentes y adultos (Bordignon, 6I).

Kohlberg fundamenta la formación moral en la madurez del juicio moral, que es una competencia y una potencialidad innata y personal, que ocurre durante a maduración de las estructuras cognitivas, en interacción con los estímulos sociales y educacionales. Una de las grandes preocupaciones de Kohlberg fue la educación moral que acontece en las escuelas. El mundo que nos toca vivir está lleno de contradicciones, que nos retan a tomar decisiones sin cesar. Nuestras opciones deben estar bien discernidas, desde el análisis minucioso y el juicio crítico que nos preparan de forma magistral para los debates abiertos sobre los dilemas morales. Se impone la cuestión de saber desde qué principios, criterios y valores éticos y morales piensan y orientan la formación los profesores. La aportación de Kohlberg permite diagnosticar en qué estadio del desarrollo moral se encuentra el educando o el adulto. La formación filosófica del profesor se hace imperiosa e inaplazable, pues su rol profesional tiene enorme trascendencia. Precisamos de un amplio bagaje antropológico, que sitúe el concepto de persona, sus caraterísticas, estructura, relaciones, expresiones y potencialidades, para fundamentar y formular los procesos con la adaptación requerida; actualizar y valorar en su justa medida los conceptos de ética y moral, con los controvertidos temas actuales de ideología de género, bioética y liberalismo individualista; y finalmente conocer los rasgos diferenciadores de los niveles de desarrollo moral de Kohlberg, para saber analizar e identificar las respuestas referidas a cada uno de los dilemas morales, desde un acompañamiento en todos los ámbitos de la educación integral de los educandos.

A este propósito Gardner, que secunda este ensayo formativo con dilemas morales, en los que los alumnos deben examinar posibles soluciones y considerar cómo reaccionarán si dentro de cinco o diez años se enfrentan a diversos dilemas en el trabajo. Por eso, advierte: "Los padres, los enseñantes y otros adultos no pueden of recer una guía directa para 
una profesión, porque no pueden saber con seguridad a qué se dedicarán los estudiantes en el futuro ni los posibles dilemas a los que se enfrentarán. Pero pueden actuar como modelos generales del trabajo ético y contribuir a fomentar unas posturas éticas adecuadas para distintas profesiones. . Por todo ello es especialmente importante que los jóvenes que se están formando empiecen a pensar en función de las "cuatro $M$ ", es decir, de misiones, modelos y espejos (mirror) en los que mirarse" (Gardner, p. I05).

\section{Breve esquema de los estadios del desarrollo moral, según Kohlberg:}

Podemos partir del principio que relaciona las teorías cognitivoevolucionistas como interaccionista, es decir, asume que la estructura mental es el producto de la interacción entre el organismo personal, las competencias individuales, las condiciones genéticas personales y la cultura, los acontecimientos y las condiciones del medio. Por lo tanto, la conclusión más pertinente es que "las estructuras de pensamiento $y$ de acción moral forman una secuencia invariable en el desarrollo moral" (Bordignon, 7I).

Resulta pertinente dar los términos claves de la psicogénesis o desarrollo cognitivo de Piaget, como punto de arranque e inspiración de los estadios de Kohlberg:

\begin{tabular}{|l|l|}
\hline DESARROLLO COGNITIVO & \multicolumn{1}{|c|}{ DESARROLLO AFECTIVO } \\
\hline $\begin{array}{l}\text { Inteligencia SENSOMOTRIZ. } \\
\text { De 6-8 meses hasta los } 2 \text { años }\end{array}$ & $\begin{array}{l}\text { Sentimientos instintivos. Reflejos } \\
\text { Intraindividual }\end{array}$ \\
\hline $\begin{array}{l}\text { Inteligencia PREOPERACIONAL } \\
\text { De 2 a } 6 \text { años. } \\
\text { Verbal, socializador. }\end{array}$ & $\begin{array}{l}\text { HETERÓNOMO: Sentimientos } \\
\text { interindividuales. Intercambios: } \\
\text { Afectivos, amor, respeto - Temor, } \\
\text { obediencia. }\end{array}$ \\
\hline $\begin{array}{l}\text { Pensamiento lógico: } \\
\text { Inteligencia OPERACIONES } \\
\text { CONCRETAS. De 6 a I I años. }\end{array}$ & $\begin{array}{l}\text { AUTÓNOMO: Sentimientos semi- } \\
\text { normativos. } \\
\text { Primeras representaciones } \\
\text { cooperativas, justicia. }\end{array}$ \\
\hline $\begin{array}{l}\text { OPERACIONES FORMALES: } \\
\text { I2-I7 años. Pensamiento } \\
\text { hipotético deductivo- Abstracto. }\end{array}$ & $\begin{array}{l}\text { Sentimientos normativos - morales. } \\
\text { Ideas sociales, escala de valores. } \\
\text { Conservación y lógica adolescente. }\end{array}$ \\
\hline
\end{tabular}


Conviene recordar que el objetivo último que se propuso Kohlberg en su proyecto piloto de discusión de los dilemas de juicio moral con grupos de alumnos fue el de fomentar la educación y el desarrollo de la conciencia moral, además del aprendizaje de la participación democrática, el sentido de la responsabilidad comunitaria y social, y de la motivación para el trabajo escolar y de la ciudadanía (Bordignon, I03).

\begin{tabular}{|l|l|}
\hline \multicolumn{1}{|c|}{ BASES DEL JUICIO MORAL } & \multicolumn{1}{c|}{$\begin{array}{c}\text { ESTADIOS DEL } \\
\text { DESARROLLO MORAL }\end{array}$} \\
\hline $\begin{array}{l}\text { EI MORAL HETERÓNOMA: } \\
\text { Actos externos, necesidades, } \\
\text { causas físicas. }\end{array}$ & $\begin{array}{l}\text { Referencia EGOCÉNTRICA: } \\
\text { Poder superior, evitar problemas, } \\
\text { responsabilidad objetiva. }\end{array}$ \\
\hline $\begin{array}{l}\text { E2 MORAL } \\
\text { INDIVIDUALISTA. } \\
\text { Objetivo instrumental y de } \\
\text { cambio. }\end{array}$ & $\begin{array}{l}\text { EGOÍSTA: Satisfacer } \\
\text { necesidades. Conciencia de } \\
\text { necesidad del actor. Reciprocidad }\end{array}$ \\
\hline $\begin{array}{l}\text { E3 MORAL } \\
\text { INTERPERSONAL: } \\
\text { Relaciones, conformidades } \\
\text { mutuas. }\end{array}$ & $\begin{array}{l}\text { BUEN CHICO. Busca agradar, } \\
\text { aprobar, ayudar. } \\
\text { Estereotipos de juicios por } \\
\text { intenciones. }\end{array}$ \\
\hline $\begin{array}{l}\text { E4 MORAL DEL SISTEMA } \\
\text { SOCIAL: Preservarlo - y de la } \\
\text { CONCIENCIA. }\end{array}$ & $\begin{array}{l}\text { Mantener el ORDEN SOCIAL } \\
\text { y la AUTORIDAD. El deber y el } \\
\text { respeto a la autoridad. }\end{array}$ \\
\hline $\begin{array}{l}\text { E5 CONTRATO SOCIAL: } \\
\text { Busca utilidad, derechos } \\
\text { individuales. }\end{array}$ & $\begin{array}{l}\text { LEGALISTA: Arbitrariedad } \\
\text { de las leyes. Respetar derechos. } \\
\text { Deber como contrato. Voluntad } \\
\text { y bienestar de la mayoría. }\end{array}$ \\
\hline $\begin{array}{l}\text { E6 PRINCIPIOS ÉTICOS } \\
\text { UNIVERSALES }\end{array}$ & $\begin{array}{l}\text { CONCIENCIA Y Y } \\
\text { PRINCIPIOS normativos. } \\
\text { Reglas sociales ordenadas, mutuo } \\
\text { respeto, universalidad lógica. } \\
\text { Confianza mutua. }\end{array}$ \\
\hline
\end{tabular}

\section{Enseñar la moral en la escuela}

La escuela es la estructura competente para la educación y no sólo para la instrucción, huyendo de un cínico reduccionismo de la cultura integral que no puede excluir el hecho religioso en la vida del ser humano, según lo muestra la antropología crítica. En la escuela se deberá formar a la persona en todas sus facetas, para satisfacer el 
anhelo de búsqueda de la verdad que habita en la mente humana. La Encíclica "Fides et Ratio", de Juan Pablo II (1998), parte de una consideración de fe y razón como "las dos alas con las cuales el espíritu bumano se eleva a la contemplación de la verdad”. Declara también la actividad filosófica -hoy desterrada de la formación básica y universitaria en los currículos- como una de las tareas más nobles de la humanidad y postula una armonía "fundamental" entre la filosofía y la fe. Se llega a afirmar en esta encíclica, a este propósito, que "...ninguna verdadera disensión puede jamás darse entre la fe y la razón” (53), aunque, lamentablemente, ha sido el reduccionismo ilustrado el que resolvió el problema con la "ceguera para el símbolo", como expresión de debilidad ante las preguntas radicales y de sentido del hombre ante la vida.

El problema pedagógico que hoy se suscita es la falta de confianza en los educadores, sea por su falta de formación, sea por sus interpretaciones personales o fundamentalistas, respecto a la religión de los padres de los educandos. Crear lazos de confianza y posibilitar opciones educativas es una exigencia de la libertad, que debe buscarse en el diálogo entre personas con formación y sentido crítico. La dimensión simbólica se impone como "rasgo esencial del mundo de lo religioso”. Este rasgo exige ser tenido muy en cuenta a la hora de la catequesis y la evangelización, como urgencia didáctica. Las corrientes laicistas quieren separar todo tipo de ideologización en las aulas, eliminando el debate auténtico sobre los problemas humanos y los valores éticos o religiosos. Ni la moral ni los valores pueden enseñarse, pues necesitan modelos referenciales, testigos, antes que maestros, como afirmaba S.S. Pablo VI.

\section{5. ¿Quién enseña hoy la moral a los jóvenes?}

El debate pone en el ojo del huracán a la escuela, pero como subsidiaria de la familia, primera célula educadora. La política no puede usurpar esta competencia a la familia, pues sería ir contra la libertad de conciencia y el principio de respeto a la pluralidad de creencias. De ahí la lógica atribución a que cada escuela tenga su carácter propio, asumido por los que optan por un proyecto educativo confesional. El Estado debe asumir esa diversidad de credos, siempre que se ajusten a 
los principios de la convivencia social, regulados por la Constitución de cada país, regla suprema de la ciudadanía en una democracia.

Recordamos todavía la alarma en la sociedad española, cuando la Fundación Cives, de la Universidad de Getafe, liderada por D. Gregorio Peces Barba, ExDefensor del Pueblo, pretendía nada más y nada menos que "cambiar la conciencia moral de la juventud española" por medio de la innovadora asignatura de "Educación para la ciudadanía". Tal osadía sólo cabía en mentes autoritarias. La revista "Padres y Maestros" dio cuenta de nuestra denuncia. Con el tiempo se descubrió el quijotesco y cínico proyecto, tramado desde el socialismo en el poder.

Los pensadores actuales, entre ellos G. Vatimo, nos señalan los tres vectores que apuntan a un retorno de la religión, en continuidad con la exigencia kantiana de una unión de la virtud con la felicidad, como postulación de una esperanza, que haga posible la síntesis de la existencia humana con su significado. Estos tres indicios son: " $\mathrm{La}$ experiencia de la muerte de aquellos a quienes se ama y por quienes se es amado; la conciencia del envejecimiento inevitable y los límites impuestos a la realización personal por una vida efímera" (Vatimo, I2-I5). La filosofía de la religión, según Kant, nos guía a responder a las tres preguntas fundamentales del ser humano: "Todos los intereses de mi razón (tanto los especulativos como los prácticos) se resumen en las tres cuestiones signientes: ¿Qué puedo saber? ¿Qué debo saber? ¿Qué puedo esperar?” (Kant: Crítica de la razón pura).

Para el pensador judío, J. Derrida, la religión es omnipresente, está clavada en la realidad humana como una dimensión a la vez extraña e inerradicable. Derrida descubre dos fuentes de la religión. A la primera la llama "lo mesiánico", es una apertura al futuro, lo que va viniendo como irrupción inesperada y perturbadora. Es una estructura general de la experiencia histórica que está en las raíces de lo democrático, generando un deseo incoercible de justicia e igualdad. La segunda fuente la llama "khôra", y la funda en el descubrimiento de lo sacro, como presupuesto del movimiento más primigenio del pensamiento, basado en la omnipresencia divina, como presencia dinámica que se comunica al hombre. (Sánchez, p. 653).

A propósito de la Refundación de la Escuela en Francia, iniciada por el Ministro de Educación, V. Peillon, el articulista de La Vie, Jean- 
Pierre Denis, se pregunta: "Cómo la moral laica podrá respetar las conciencias en un contexto de ignorancia del becho religioso?" (La Vie: 25.04.2013, p. 5). Al hablar de temas críticos: Darwin, la creación del mundo, la Soah, los derechos de la mujer, etc., se debe evitar herir las conciencias, por las ideas antifundamentalistas que puedan suscitarse. Este riesgo es asumido por los docentes que se refugian en el silencio, cuando llegan los temas críticos. La entrada de la moral en las aulas suscita más cuestiones que respuestas, en su mayoría ambiguas, en boca del Ministro. Puede sonar a innovación, pero con poca credibilidad por la poca intensidad - una hora semanal- y sólo en los niveles de Secundaria.

Una cita para recordar, de F. Buisson (I84I-1932), uno de los padres fundadores de la escuela de la III República francesa: "La moral laica, escribía este escritor protestante liberal, está estrechamente ligada a la moral evangélica. En otros términos, es deudora al Evangelio, que es su fuente". Constatamos la necesidad de fundamentar el "pensamiento débil" de nuestra sociedad, para llegar al salto de la trascendencia que es esencial al ser humano. Pensar la religión es ahora necesario, si se quieren afrontar los problemas de la propia razón, del hombre, de la cultura. Pero existe otro camino específico en las aulas: Formar las mentes, enseñar a pensar, formar en la interioridad con bases antropológicas y sociocognitivas, preparar al niño, desarrolando sus habilidades cognitivas, para los saltos de la abstracción y de elaboración interior, mental, que va a exigir pensar y seguir aprendiendo toda su vida.

Enseñar a pensar, como puerta hacia el descubrimiento del sentido crítico de la vida, como síntesis de la visión interdisciplinar y de la lógica contrastada con la experiencia vital. El ser humano es, por definición, creador de imágenes, decodificador de símbolos, elaborador de proyectos y abstracciones: Un genial transformador de imágenes, pero, sobre todo, un ser único e irrepetible, en relación con los demás, con el universo, con sus creencias. ¿No será el auténtico camino el de construir mentes, formar la inteligencia? Los mejores y más revolucionarios educadores así lo creen:

"El gobernante que decrete como obligatorias clases de inteligencia a todos los niveles de la enseñanza, habrá logrado un beneficio para su país, para la humanidad y para su propia 
figura histórica, que nadie nunca le podrá desconocer...”. "Estoy absolutamente convencido de que el día en que la humanidad llegue a la conclusión de que la inteligencia es algo que puede aprenderse, ese día la humanidad habrá dado, en el plano de lo intelectual, el paso más importante de la Historia”. (L.A. Machado, II8-II9).

"En cualquier caso, la supervivencia y la prosperidad de nuestra especie dependerán de la educación de unos potenciales exclusivamente humanos" (Gardner, p. II2).

\section{Referencias bibliográficas}

Bauman, Z. (2009). El arte de la vida. Bercelona: Paidós.

Bordignon, N.A. (2013). El desarrollo moral de Kobllergen la E.S. Porto Alegre: EAE. Camps, V. (1993). Paradojas del individualismo. Barcelona: Drakontos.

Changeux, J.P. y Ricoeur, P. (1998). Lo que nos bace pensar. Barcelona: Península. Compte-Sponville, A. Ferry, L. (1998). La sagesse des modernes. Paris: Robert Laffont.

Domingo, A. (200I). Lo que usted estudió y nunca debió olvidar de Ética. Madrid: Acento.

Ferry, L. (2007). Aprender a vivir. Filosofía para mentes jóvenes. Madrid: Taurus.

Gardner, H. (2005). Las cinco mentes del futuro. Barcelona: Paidós.

Kant, E. (1988). Crítica de la razón pura. Madrid: Alfaguara.

Laín, P. (1999). Qué es el hombre. Evolución y sentido de la vida. Oviedo: Nobel.

Machado, L.A. (1990). La revolución de la inteligencia. Barcelona: Seix Barral ( $5^{\mathrm{a}} \mathrm{ed}$.).

Morin, E. (2002). La mente bien ordenada. Barcelona: Seix Barral (4 ed).

Sánchez Nogales, J.L. (2003). Filosofía y fenomenología de la Religión. Salamanca: Secretariado Trinitario.

Tébar, L. (2009). El profesor mediador del aprendizaje. Bogotá: Magisterio.

Vatimo, G. (1996). Creer que se cree. Barcelona: Paidós. 